\title{
BMJ Open Impact of local health insurance schemes on primary care management and control of hypertension: a cross- sectional study in Shenzhen, China
}

\author{
Haitao $\mathrm{Li}^{1}{ }^{1}$ Zhu Wu, ${ }^{2}$ Xia Hui, ${ }^{3}$ Yanhong Hu
}

To cite: Li H, Wu Z, Hui X, et al. Impact of local health insurance schemes on primary care management and control of hypertension: a cross-sectional study in Shenzhen, China. BMJ Open 2019;9:e031098. doi:10.1136/ bmjopen-2019-031098

- Prepublication history for this paper is available online. To view these files, please visit the journal online (http://dx.doi. org/10.1136/bmjopen-2019031098).

Received 17 April 2019

Revised 18 September 2019

Accepted 19 September 2019

Check for updates

(C) Author(s) (or their employer(s)) 2019. Re-use permitted under CC BY-NC. No commercial re-use. See rights and permissions. Published by BMJ.

${ }^{1}$ Shenzhen University General Hospital, Shenzhen University, Shenzhen, China

${ }^{2}$ School of Management, Wuhan University, Wuhan, China

${ }^{3}$ Department of Choronic Disease, Longhua District Center for Chronic Disease Prevention and Control, Shenzhen, China

${ }^{4}$ Murdoch Children's Research Institute, University of

Melbourne, Melbourne, Victoria, Australia

Correspondence to

Dr Haitao Li;

htli1223@szu.edu.cn

\section{ABSTRACT}

Background In China, the local health insurance coverage is usually related to timely reimbursement of hypertensive care in primary care settings, while health insurance that is not local could represent an obstacle for accessibility and affordability of primary care for hypertensive patients. Objective To investigate whether local health insurance schemes have a positive impact on hypertension management and control.

Design We performed an on-site, face-to-face, patients survey in community health centres (CHCs) in Shenzhen, China.

Setting and participants Hypertensive patients seeking healthcare from $\mathrm{CHCs}$ were selected as study participants using a systematic sampling design.

Main measures We obtained information about insurance status, social capital, drug treatment and control of hypertension. Multivariable stepwise logistic regression models were constructed to test the associations between insurance status and hypertension management, as well as insurance status and social capital.

Results A total of 867 participants were included in the final study analysis. We found that the participants covered by local insurance schemes were more likely to be managed in primary care facilities $(61.1 \%$ vs $81.9 \%$; $\mathrm{OR}=2.58,95 \% \mathrm{Cl}: 1.56$ to 4.28 ), taking antihypertensive drugs $(77.2 \%$ vs $88.0 \%$; $\mathrm{OR}=2.23,95 \% \mathrm{Cl}: 1.37$ to $3.62)$ and controlling blood pressure $(43.0 \%$ vs $52.4 \%$; $\mathrm{OR}=1.46,95 \% \mathrm{Cl}: 1.03$ to 2.07$)$ when compared with those with insurance coverage that is not local. The participants covered by local insurance schemes reported a higher score of perceived generalised trust than those without ( 4.23 vs $3.97 ; \mathrm{OR}=0.74,95 \% \mathrm{Cl}: 0.53$ to 0.86 ). Conclusion Our study demonstrates that local health insurance coverage could help improve management and control of hypertension in a primary care setting. Policymakers suggest initiating social interventions for better management and control of hypertension at the primary care level, although the causal pathways across insurance status, social capital and control of hypertension deserve further investigations.

\section{INTRODUCTION}

Hypertension is one of the major causes of cardiovascular disease and represents a significant public health problem in China. The
Strengths and limitations of this study

A study in a large Chinese city to investigate the impact of local health insurance schemes on the management and control of hypertension at the primary care level.

- Data were collected by trained interviewers with standardised protocols and instruments.

- Recall bias is possible because a self-reported interviewing approach was used to collect data.

- The interpretation of the study findings should be based on the local context, given the different social capital measurements.

prevalence of hypertension in China dramatically increased from $19 \%$ in $2002^{1}$ to $34 \%$ in $2010 .^{2}$ In 2015 , there were an estimated more than 200 million hypertensive patients in China. Blood pressure reduction significantly decreases the risk of cardiovascular disease. ${ }^{3}{ }^{4}$ However, the control of hypertension is still suboptimal due to low awareness and treatment rates. ${ }^{5}{ }^{6}$ Following the WHO's suggestions, the Chinese government is emphasising the role of primary care in improving the current factors that contribute to hypertension.

In urban China, primary care services are usually provided by community health centres (CHCs) that are responsible for chronic diseases management, including hypertension. According to the hypertension management guidelines, primary care providers should perform blood pressure measurements for residents seeking healthcare services in CHCs. Health records should then be established for hypertensive patients. Non-pharmaceutical and pharmaceutical treatments are initiated after assessing patients' blood pressure levels and coexisting cardiovascular risk factors. It has been shown that hypertensive patients managed at primary care clinics have better 
blood pressure control. The study by Li $e$ t $a l^{7}$ found that in patients with hypertension managed by primary care providers, their hypertension control rate was about $80 \%$, a higher number than the general population. However, there is still room for improvement in hypertension management and control.

Health insurance has been positively associated with hypertension treatment and control. Murasko ${ }^{8}$ found that patients without insurance were less likely to utilise hypertensive care. The study by Brooks et at showed that fewer uninsured patients received treatment for hypertension and high cholesterol, which are risk factors for cardiovascular diseases. Besides, more insured patients received diagnostic screenings for diabetes, cholesterol and hypertension. ${ }^{10}$ Hendriks et $a l^{11}$ found that participation in one insurance programme could increase access and improve healthcare quality leading to a significant long-term reduction in blood pressure. Different health insurance programmes have been associated with medication selection for hypertension treatment. ${ }^{12}$

The Chinese government has been undertaking an ongoing healthcare reform that emphasises establishing insurance systems, mainly to cover the rural population. There are three social health insurance schemes: (1) basic medical insurance scheme for urban employees, (2) basic medical insurance scheme for urban residents in urban areas and (3) rural cooperative medical insurance scheme in rural areas. The Chinese government is committed to having universal health coverage. By the end of 2017, more than $95 \%$ of the Chinese population was covered by social health insurance. ${ }^{13}$ All three health insurance schemes are administered at the county or municipal level. The reimbursement rate varies by regions and by healthcare facility type.

Shenzhen is the first Chinese Special Economic Zone located in south China and cross-board with Hong Kong. Due to its fast economic growth, Shenzhen attracts millions of internal migrant workers from the rural countryside of China. These people are less professionally trained and with a lower level of educational background. Shenzhen government has launched three types of social health insurance schemes, which include comprehensive medical insurance scheme, a medical insurance scheme for migrant employees and hospitalisation insurance scheme to cover both the locals and the migrants. However, for migrants, joining local health insurance schemes are voluntary. Therefore, many of the migrants are not covered by local health insurance schemes, especially unemployed migrants. If the migrants without local insurance coverage seek medical services, they are required to pay the full service cost out of their pocket and can only be reimbursed when they return to their hometowns.

This study aims to investigate whether the participation in local health insurance scheme has an impact on hypertension management and control. The study will also examine the social capital factors that could be related to participation in local health insurance schemes.
METHODS

\section{Patient and public involvement}

Participants and the public were not involved in the development of the research questions, study or recruitment.

\section{Recruitment and sampling}

We performed a cross-sectional study in Shenzhen, China. Employing multistage cluster random sampling methods, primary care facilities (ie, CHC) were selected as the study setting. In the first stage, we chose one district, Longhua District (which includes six subdistricts) in Shenzhen through a simple random sampling method. In the second stage, we obtained all the names of CHCs in every subdistrict from the Health Bureau of Longhua District. Simple random sampling methods were used to draw two CHCs from each subdistrict. Twelve CHCs were randomly selected.

We conducted an on-site survey. The sampling frame was based on a systematic sampling design; we selected every fifth care user who attended CHCs. Our selection criteria were participant willing to participate in this study, $\geq 18$ years old and being a Shenzhen resident for no less than 6 months. The selected participants answered whether they had hypertension history or not. Simultaneously, blood pressure was examined by primary care providers. The selected participants had a history of hypertension whose diagnosis was confirmed by medical professionals or the blood pressure was $\geq 140 / 90 \mathrm{mmHg}$ during the first visit examination. A total of 1200 participants were recruited (100/CHC). Face-to-face in-depth interviews were conducted in September 2017 by welltrained interviewers. The response rate was $87.2 \%$ or 1046 participants.

\section{Variables of the characteristics}

According to Donabedian's framework, the management of hypertension was measured using process and outcome indicators. ${ }^{14}$ Health outcome was measured by hypertension control, which was defined as achieving blood pressure levels below 140 and $90 \mathrm{~mm} \mathrm{Hg}$ for systolic blood pressure and diastolic blood pressure, respectively. The respondents were then divided into two categories: (1) optimal $(<140 / 90 \mathrm{~mm} \mathrm{Hg})$ and (2) suboptimal $(\geq 140 / 90 \mathrm{~mm} \mathrm{Hg})$. The process indicators included the primary care management and pharmaceutical treatment of hypertension. The participants answered whether they received the hypertension management at CHCs ( $1=y e s$, $2=$ no, $3=$ do not know). The participants were also asked if they were currently taking antihypertensive drugs (1=yes, 2=no).

Participants' individual social capital information was obtained using the decomposition of participation in organisations (formal networks potentially bridging), social contacts (informal networks indicative of bonding ties) and generalised trust. The items used for the measurement of social capital were listed below (table 1). An unweighted sum score was calculated for participation 
Table 1 Questions used for social capital measurement

\begin{tabular}{ll} 
Social capital & Answers \\
\hline Participation & Yes No
\end{tabular}

Are you involved with any of these organisations?

Political parties

Sports teams

Associations like technology

Religious organisations

Volunteering

Hobbies

Colleagues

Family

Fellow-townsman

Classmates

\section{Social contacts}

Never Seldom Sometimes

Frequently Always

How often do you contact your family members or relatives?

How often do you contact your friends?

How often do you contact your neighbours?

\section{Generalised trust}

Never Seldom Sometimes Frequently Always

Would you say that most people can be trusted, or that you cannot

be too careful?

in organisations (range 0-10), social contacts (range 3-15) and trust (range 1-5).

Health insurance information was documented by asking the following question: by which of the following insurance schemes are you covered? (1=basic medical insurance scheme for urban employees, $2=$ basic medical insurance scheme for urban residents, 3=new rural cooperative medical insurance scheme, 4=comprehensive medical insurance scheme, $5=$ medical insurance scheme for migrant employees, $6=$ hospitalisation insurance scheme, $7=$ do not know if covered by any insurance scheme). The participants were grouped into two categories, (1) individuals covered by insurance schemes 4,5 or 6 were labelled as 'local insurance,' and (2) individuals covered by insurance schemes 1,2 or 3 were labelled as 'with insurance but not local (without local insurance).' Covariates were also recorded (table 2).

\section{Statistical analyses}

SPSS V.20.0 (IBM, USA) was used to conduct all the analyses. Descriptive statistics of the participants' characteristics were conducted (eg, age, gender, education, occupation, years with hypertension, family history of hypertension). A comparison of sociodemographic factors, social capital and management of hypertension, between the participants with and without local insurance, was performed using the $\chi^{2}$ test (or t-test whenever it was appropriate). Multiple logistic regression models were constructed to test the associations between insurance status and management of hypertension, as well as between insurance status and social capital. Confounders such as age, gender, education, occupation, years with hypertension and family history of hypertension were adjusted in the regression models. ORs with 95\% CI were applied in the analysis with $\mathrm{p}<0.05$ (statistically significant).

\section{RESULTS}

The final analysis did not include the participants who did not know their insurance status or were not covered by any insurance scheme. A total of 867 participants were analysed in this study, local health insurance covered 432

Table 2 Covariates recorded by the current study

\begin{tabular}{|c|c|}
\hline Variables & Answers \\
\hline Age & $\begin{array}{l}1=18-44 \text { years, } 2=45-60 \text { years, } \\
3=>60 \text { years }\end{array}$ \\
\hline Gender & $1=$ male, $2=$ female \\
\hline Education level & $\begin{array}{l}1=\text { primary school and below, } \\
2=\text { middle school, } 3=\text { high school } \\
\text { or equivalent, } 4=3 \text { year college } \\
\text { and above }\end{array}$ \\
\hline Occupation & 1=employed, $2=$ unemployed \\
\hline $\begin{array}{l}\text { Year of hypertension } \\
\text { since being diagnosed }\end{array}$ & Years \\
\hline $\begin{array}{l}\text { Family history of } \\
\text { hypertension }\end{array}$ & $1=$ yes, $2=$ no, $3=$ unknown \\
\hline Registration & $1=$ locals, $2=$ migrants \\
\hline
\end{tabular}


Table 3 Sociodemographic characteristics of the participants by insurance status

\begin{tabular}{|c|c|c|c|c|}
\hline \multirow[b]{2}{*}{ Characteristics } & \multirow{2}{*}{$\begin{array}{l}\text { All } \\
\mathrm{n}(\%)\end{array}$} & \multirow{2}{*}{$\begin{array}{l}\text { Without local insurance } \\
\text { n (\%) }\end{array}$} & \multirow{2}{*}{$\begin{array}{l}\text { With local insurance } \\
\mathrm{n}(\%)\end{array}$} & \multirow{2}{*}{$\begin{array}{l}\mathbf{P} \\
\text { value* }\end{array}$} \\
\hline & & & & \\
\hline Age (mean, SD), years & $55.5(11.04)$ & $60.0(0.48)$ & $50.9(0.50)$ & \\
\hline $45-60$ & 409 (48.3) & $167(38.9)$ & $242(57.9)$ & \\
\hline$>60$ & $294(34.7)$ & $227(52.9)$ & $67(16.0)$ & \\
\hline Male & $503(60.7)$ & $196(47.5)$ & 307 (73.8) & $<0.001$ \\
\hline Female & $326(39.3)$ & $217(52.5)$ & $109(26.2)$ & \\
\hline \multicolumn{5}{|l|}{ Education } \\
\hline Primary school and below & $219(25.3)$ & $153(35.3)$ & $66(15.2)$ & $<0.001$ \\
\hline Middle school & $297(34.3)$ & $134(30.9)$ & $163(37.6)$ & \\
\hline \multicolumn{5}{|l|}{ Registration } \\
\hline Locals & $133(16.0)$ & $0(0.0)$ & $133(30.4)$ & - \\
\hline Migrants & $700(84.0)$ & $396(100.0)$ & $304(69.6)$ & \\
\hline \multicolumn{5}{|l|}{ Occupation } \\
\hline Employed & $484(55.8)$ & $142(32.6)$ & $342(79.2)$ & $<0.001$ \\
\hline Unemployed & $383(44.2)$ & $293(67.4)$ & $90(20.8)$ & \\
\hline Year of hypertension (mean, SD) & $6.0(5.94)$ & $6.8(0.32)$ & $5.2(0.26)$ & $<0.001$ \\
\hline \multicolumn{5}{|l|}{ Family history of hypertension } \\
\hline Yes & $384(45.2)$ & $188(43.6)$ & $196(46.8)$ & $<0.001$ \\
\hline
\end{tabular}

${ }^{*}$ Chi-square test; year of hypertension was continuous with a mean (SD) presented; mean age (SD) was presented.

participants while 435 participants were covered by health insurance that is not local. The participants mean age was 55.5 years. The majority were male $(60.7 \%)$, migrants $(84.0 \%)$ and employed $(55.8 \%)$. The participants mean duration of hypertension was 6.0 years. Almost half of the participants $(45.2 \%)$ had a family history of hypertension. Compared with those without local insurance coverage, the participants with local insurance schemes were more likely to be younger $(60.0$ vs $50.9, \mathrm{p}<0.001)$, male $(73.8 \%$ vs $47.5 \%, \mathrm{p}<0.001)$, with a higher education level $(\mathrm{p}<0.001)$, employed $(79.2 \%$ vs $32.6 \%, \mathrm{p}<0.001)$ and with a shorter duration of hypertension (6.8 vs 5.2, $\mathrm{p}<0.001$ ) (table 3).

The participants covered by local insurance schemes were more likely to be managed in primary care facilities $(61.1 \%$ vs $81.9 \%, \mathrm{p}<0.001)$, take antihypertensive drugs $(77.2 \%$ vs $88.0 \%, \mathrm{p}<0.001)$ and achieve blood pressure control targets $(43.0 \%$ vs $52.4 \%$, $\mathrm{p}<0.001)$ when compared with participants without local insurance coverage. After adjusting for sociodemographic variables, the statistically significant differences remained for primary care management $(\mathrm{OR}=2.58,95 \% \mathrm{CI}: 1.56$ to 4.28), pharmaceutical treatment ( $\mathrm{OR}=2.23,95 \%$ CI: 1.37 to 3.62) and hypertension control rate ( $\mathrm{OR}=1.46,95 \% \mathrm{CI}$ : 1.03 to 2.07 ) (table 4 ).

After adjustments were made for sociodemographic variables in all the participants, the individuals covered by local insurance schemes reported a higher score of perceived generalised trust than those without (3.97 vs 4.23; $\mathrm{OR}=0.74,95 \% \mathrm{CI}: 0.53$ to 0.86 ). However, there were no statistically significant differences in participation and social contacts between the participants with and without local insurance (table 5).

\section{DISCUSSION}

The present study compared primary care management, pharmaceutical treatment and hypertension control among hypertensive patients with and without local health insurance coverage. We also investigated whether social capital made a difference between hypertensive participants with and without local health insurance coverage. We found that hypertensive patients with local health insurance coverage were more likely to be under primary care management, take antihypertensive drugs and achieve blood pressure control targets. This study 
Table 4 Treatment and health outcomes of hypertensive patients by insurance status

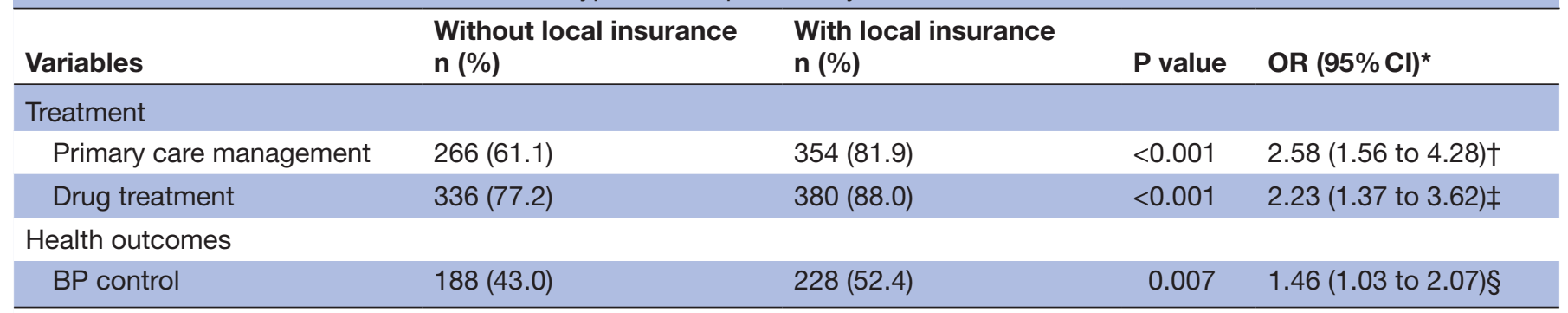

*Multiple logistic regression models were performed in the participants without local insurance coverage as the reference group. The covariates adjusted included age, gender, education, occupation, year of hypertension and family history.

$\dagger \mathrm{P}<0.001$

$\ddagger \mathrm{P}<0.01$

$\S \mathrm{P}<0.05$

$\mathrm{BP}$, blood pressure.

found that trust was also a factor that facilitates participation in local health insurance schemes.

Our results also showed that hypertensive patients with local health insurance schemes had better management and control of hypertension than those without local health insurance coverage. Previous studies have documented the importance of insurance in the use of antihypertensive medications. The study by Ahluwalia et $a l^{15}$ showed that patients with Medicaid coverage had significantly higher rates of antihypertensive drugs use compared with uninsured. Blustein ${ }^{16}$ found that patients with insurance coverage have increased access to antihypertensive medications. Adams $e t ~ a l^{17}$ further demonstrated the impact on the use of antihypertensive medications by different types of insurance. The study by Guo $e a^{12}$ also showed that insurance type had a statistically significant influence on the choices of different antihypertensive drugs. The study by Dalton $e t a l^{18}$ suggested that variation in hypertension management could be more associated with health system structure, especially the type of healthcare access provided by different insurance coverages.

This study showed that social capital, such as trust, was positively associated with participation in local health insurance schemes, which is similar to previous findings. Donfouet and Mahieu ${ }^{19}$ found that social capital had a positive impact on rural households' willingness to pay for community-based health insurance. $\mathrm{Hsiao}^{20}$ also found that persons with higher levels of social capital were more likely to use community-based health insurance. The study by Fenenga $e t a l^{21}$ also confirmed that people living in low social capital communities were significantly less likely to participate in the scheme than people living in communities with rich social capital. A study in China by Zhang et $a l^{22}$ indicated that individual-level social capital in trust significantly increased the proportion of farmers who were willing to join the new rural cooperative medical insurance scheme. Our study suggests that social interventions may be plausible to promote hypertensive patients' enrolment in local health insurance schemes; however, causal pathways among social capital and participation of local health insurance schemes deserve further studies.

This study has some limitations that should be mentioned. First, the generalisability of the study findings was limited. The participants were selected from primary care facilities, which prevents the generalisation of the study findings to a general population of hypertensive patients. Second, recall bias could not be avoidable because a self-reported interviewing approach was used to collect data. Third, given the different measurements of social capital, the interpretation should be based on a local context. Last but not least, there might be other confounders that we did not measure in the current study, although adjustments were made for the most critical socioeconomic confounders.

Table 5 Social capital of the participants by insurance status

\begin{tabular}{lcrrr}
\hline & Without local insurance mean (SD) & With local insurance mean (SD) & P value & OR (95\% Cl)* \\
\hline All participants & & & & \\
\hline Organisations & $2.03(0.11)$ & $2.20(0.09)$ & 0.262 & $0.97(0.88$ to 1.07$)$ \\
Contacts & $10.47(0.09)$ & $10.66(0.10)$ & $0.1840 .95(0.86$ to 1.05$)$ \\
Trust & $3.97(0.04)$ & $4.23(0.03)$ & $<0.0010 .74(0.53$ to 0.86$) \dagger$ \\
\hline
\end{tabular}

${ }^{*}$ Multiple logistic regression models in the participants covered by local insurance schemes as the reference group.

$\dagger \mathrm{P}<0.01$ 


\section{CONCLUSION}

Our study suggests that local health insurance coverage could play an essential role in improving hypertension management and control at the primary care level. The study also implies that social capital, such as trust, could facilitate hypertensive patients' participation in local health insurance schemes. Policymakers suggest initiating social interventions for improvements in the management and control of hypertension at the primary care level, although the causal pathways across insurance status, social capital and control of hypertension deserve further investigations.

Acknowledgements The authors would like to thank all the participants and staff who help us to obtain and analyse data for this study. The authors would also like to thank the financial institutions that provided funds for this research.

Contributors HL conceived the study. HL and ZW participated in the study's design, data collection and analysis. HL and XH drafted the manuscript and were responsible for data interpretation. YH contributed to intellectual input and manuscript revision. All the authors read and approved the final manuscript.

Funding This study was funded by the Natural Science Foundation of Guangdong Province (2017A030310439, 2018A030313863), the Natural Science Foundation of Shenzhen University (827000245) and the Longhua Science and Technology Innovation Project (2017026).

Competing interests None declared.

Patient consent for publication Not required.

Ethics approval The authors obtained ethical study approval from Shenzhen University General Hospital, Shenzhen University.

Provenance and peer review Not commissioned; externally peer reviewed.

Data availability statement All data relevant to the study are included in the article or uploaded as supplementary information.

Open access This is an open access article distributed in accordance with the Creative Commons Attribution Non Commercial (CC BY-NC 4.0) license, which permits others to distribute, remix, adapt, build upon this work non-commercially, and license their derivative works on different terms, provided the original work is properly cited, appropriate credit is given, any changes made indicated, and the use is non-commercial. See: http://creativecommons.org/licenses/by-nc/4.0/.

\section{REFERENCES}

1 Wu Y, Huxley R, Li L, et al. Prevalence, awareness, treatment, and control of hypertension in China: data from the China national nutrition and health survey 2002. Circulation 2008;118:2679-86.
2 Gao Y, Chen G, Tian H, et al. Prevalence of hypertension in China: a cross-sectional study. PLoS One 2013;8:e65938.

3 MacMahon S, Peto R, Cutler J. Blood pressure, stroke, and coronary heart disease *1Part 1, prolonged differences in blood pressure: prospective observational studies corrected for the regression dilution bias. The Lancet 1990;335:765-74.

4 Cutler JA. High blood pressure and end-organ damage. J Hypertens Suppl 1996;14:S3-6.

5 Feng XL, Pang M, Beard J. Health system strengthening and hypertension awareness, treatment and control: data from the China health and retirement longitudinal study. Bull World Health Organ 2014;92:29-41.

6 Gu D, Reynolds K, Wu X, et al. Prevalence, awareness, treatment, and control of hypertension in China. Hypertension 2002;40:920-7.

$7 \mathrm{Li} \mathrm{H}$, Wei X, Wong MC, et al. A comparison of the quality of hypertension management in primary care between Shanghai and Shenzhen: a cohort study of 3196 patients. Medicine 2015;94:e455.

8 Murasko JE. Gender differences in the management of risk factors for cardiovascular disease: the importance of insurance status. Soc Sci Med 2006;63:1745-56.

9 Brooks EL, Preis SR, Hwang S-J, et al. Health insurance and cardiovascular disease risk factors. Am J Med 2010;123:741-7.

10 Rivera-Hernandez M, Galarraga O. Type of insurance and use of preventive health services among older adults in Mexico. J Aging Health 2015;27:962-82.

11 Hendriks ME, Rosendaal NTA, Wit FWNM, et al. Sustained effect of health insurance and facility quality improvement on blood pressure in adults with hypertension in Nigeria: a population-based study. Int $J$ Cardiol 2016;202:477-84.

12 Guo JD, Liu GG, Christensen DB, et al. How well have practices followed guidelines in prescribing antihypertensive drugs: the role of health insurance. Value in Health 2003;6:18-28.

13 Ministry of Health. 2018 China health statistical Yearbook. Beijing, 2018.

14 Donabedian A. The quality of care. How can it be assessed? JAMA 1988;260:1743-8.

15 Ahluwalia JS, McNagny SE, Rask KJ. Correlates of controlled hypertension in indigent, inner-city hypertensive patients. J Gen Intern Med 1997;12:7-14.

16 Blustein J. Drug coverage and drug purchases by Medicare beneficiaries with hypertension. Health Aff 2000;19:219-30.

17 Adams AS, Soumerai SB, Ross-Degnan D. Use of antihypertensive drugs by Medicare enrollees: does type of drug coverage matter? Health Aff 2001;20:276-86.

18 Dalton ARH, Vamos EP, Harris MJ, et al. Impact of universal health insurance coverage on hypertension management: a cross-national study in the United States and England. PLoS One 2014;9:e83705.

19 Donfouet HPP, Mahieu P-A. Community-Based health insurance and social capital: a review. Health Econ Rev 2012;2:5.

20 Hsiao W. Unmet health needs of two billion: is community financing a solution? Washington DC: World Bank, 2001.

21 Fenenga CJ, Nketiah-Amponsah E, Ogink A, et al. Social capital and active membership in the Ghana National Health Insurance Scheme a mixed method study. Int $J$ Equity Health 2015;14:118.

22 Zhang L, Wang $\mathrm{H}$, Wang L, et al. Social capital and farmer's willingness-to-join a newly established community-based health insurance in rural China. Health Policy 2006;76:233-42. 